\title{
ATTITUDE AND PERCEPTION OF HEALTHCARE PROFESSIONALS IN OGUN STATE TOWARDS THEIR VISUAL HEALTH
}

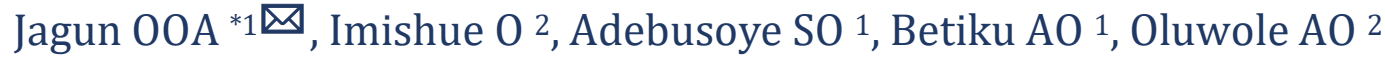 \\ ${ }^{* 1}$ Department of Surgery, Babcock University. Ilishan-Remo. Ogun State. Nigeria \\ 2 Department of Medicine, Babcock University. Ilishan-Remo. Ogun State. Nigeria
}

DOI: https://doi.org/10.29121/granthaalayah.v8.i7.2020.728

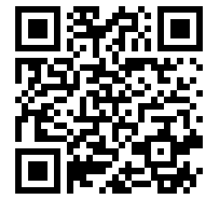

Article Type: Research Article

Article Citation: Jagun OOA, Imishue 0 , Adebusoye SO, Betiku AO, and Oluwole AO. (2020). ATTITUDE AND PERCEPTION OF HEALTHCARE PROFESSIONALS IN OGUN STATE TOWARDS THEIR VISUAL HEALTH. International Journal of Research GRANTHAALAYAH, 8(7), 185-191. https://doi.org/10.29121/granthaa layah.v8.i7.2020.728

Received Date: 13 July 2020

Accepted Date: 31 June 2020

Keywords:

Visual Health

Attitude

Perception

Professionals

\section{ABSTRACT}

Background: A good attitude towards their visual health is important to every health care professional.

Methods: A cross-sectional study. An online survey was conducted amongst health professionals in Ogun State between May 18th and June 17 th 2020.

Results: 154 respondents participated. Mean age was $39.2 \pm 8.1$ years (22yrs to 62yrs) and 84 (54.5\%) respondents were males. Respondents included Medical doctors (50.6\%), Nurses (33.1\%) and others $(16.3 \%)$. Only 63 (41\%) had a dilated ophthalmoscopy carried out on them and 112 $(72.7 \%)$ respondents visit the eye clinic only when there is a compliant.

Over $70 \%$ of respondents were aware of the listed common eye conditions (Cataract, Glaucoma, Refractive errors, Diabetic eye diseases and Retinal diseases) while 30\% had never had no knowledge of them.

Refractive errors were the most common condition previously diagnosed in 35\% of the respondents followed by Glaucoma 8 (5.2\%). 10 $(6.5 \%)$ respondents were aware of Eye banking in Nigeria and $41(27 \%)$ were willing to give consent to donate their eyes after death.

Conclusion: There was a poor attitude to assessing visual health care amongst the HCP and also a poor knowledge of Eye banking and its importance for vision restoration.

\section{INTRODUCTION}

Visual health is an important aspect of health that promotes good vision and prevention of blindness 1 . The eyes play one of the most important roles in mobility, daily living and normal vision entails having a visual acuity (VA) of at least $6 / 6$ with or without correction2.

Impairment of vision (VI) according to the International Classification of Disease [ICD] 11 range from mild VI (VA worse than 6/12) to blindness (VA worse than 3/60 after correction)2. Globally, VI and blindness are estimated to affect about 2.2 billion people and this is mainly caused by uncorrected refractive errors (including presbyopia), Cataract, Glaucoma, Cornea opacity, Diabetic retinopathy and Trachoma3. The prevalence of VI in low and middleincome population like Nigeria is about four times that of high income population3.

An important aspect of visual health not extensively promoted or accepted in Africa is Ocular tissue banking. This is the regulated post mortem donation and storage of disease-free eyes mainly for cornea grafting to restore vision 4 and thus preserve the visual health of the recipient.

Health care professionals are expected to have a good knowledge of their visual status to ensure

(C) 2020 The Author(s). This is an open access article distributed under the terms of the Creative Commons Attribution License, which permits unrestricted use, distribution, and reproduction in any medium, provided the original author and source are credited. 
optimum visual health, maximum productivity in life and be good health role models for their patients5. Some studies have however shown that HCP often neglect their health in favor of professional obligations5. An American study which compared the health behaviors of some HCP and non-HCP found no significant differences in the wrong choices of Dental visits, Colonoscopy, Alcohol drinking habits, smoking, being overweight) etc within the 2 groups studied6. Wiskar however documented that Physicians who carry out a healthy lifestyle and medical habits are more likely to counsel their patients to do the same despite the different health challenges the patients may be going through5.

The main aim of this study is to determine the outlook of health professionals in Ogun State towards their visual health and their predisposition towards ocular tissue banking choices.

\section{MATERIALS AND METHODS}

A cross-sectional study. A semi-structured online questionnaire was developed based on an online poll commissioned by Research America in 20167. The online survey was conducted amongst health professionals in Ogun State [one of the 36 states in Nigeria] by sending the survey questionnaire via email and WhatsApp using contact details obtained from individual professional groups. Consecutive individuals in each group lists were contacted until a total of 250 participants were selected. The responses from the survey were collected over four weeks between 18th May and 17th June 2020.

All health professionals who responded were taken to have given their consent to participate in the study. The survey link was programmed to accept only one response per participants to avoid duplication of responses.

Results: One hundred and fifty-four responses were received out of 250 selected health professionals, giving a respondent rate of $61.6 \%$. The mean age of the respondents was $39.2 \pm 8.1$ years (yrs) with an age range of $22 y$ ys to 62yrs. Eighty-four (54.5\%) respondents were males, 83.8\% (129) were married and 87\% (134) were Christians (Table 1).

Respondents were made up of Medical doctors (50.6\%), Nurses (33.1\%) and Others (16.3\%) which included medical laboratory technicians (3.9\%), pharmacist (5.9), physiotherapist (4.6\%) and Clinical psychologist (1.9\%). A majority (61.6\%) of the respondents have been practicing their profession for over 10 years but only $30(19.5 \%)$ had medical insurance coverage (Table 1 ).

Only $49(31.8 \%)$ respondents rated their general health as being excellent while $103(67 \%)$ felt their general health good even though 38 (25\%) of them had specific health conditions which included Hypertension, diabetes, peptic ulcer, asthma, Arthritis, Sickle cell disease and bipolar disorder.

One hundred and thirty-one (85\%) of the respondents had undergone an eye examination in the past but only $63(41 \%)$ had ever had a dilated ophthalmoscopy carried out on them. The frequency of visitations to the eye clinic was random for 112 (72.7\%) respondents and only 13 (8.4\%) had regular eye checkup of at least every 6 months (Table 2). Forty percent of those that had insurance coverage had regular eye checkups, while only $24.2 \%$ of the uninsured HCP had regular eye checkups but this was not found to be statistically significant.

Over $70 \%$ of respondents were aware of the listed common eye conditions (Cataract, Glaucoma, Refractive errors, Diabetic eye diseases and Retinal diseases) while 30\% had no knowledge of any of these conditions.

Refractive errors were the most common condition previously diagnosed in 35\% of the respondents followed by Glaucoma $8(5.2 \%)$ even though $30(19.5 \%)$ had a family history of Glaucoma. There was a statistically significant association ( $\mathrm{P}=0.01)$ between increase age and having an eye condition in those aged 40 yrs and above.

There was no significant association between the gender of the respondents or the group of HCP and the presence of any eye condition.

Only $10(6.5 \%)$ respondents were aware of Eye banking in Nigeria and 41 (27\%) were willing to give consent to donate their eyes after death. Reasons for unwillingness towards eye donation are listed in Fig II. There however was a significant association $(p=0.01)$ between the nature of HCP and their willingness to donate their eyes; with doctors being most willing followed by the 'others' and lastly the nurse being least willing. The religion of the HCP was also found to show a significant association $(\mathrm{P}=0.01)$ with their willingness to donate their eyes with Christians been more willing than Muslims. 
Jagun OOA, Imishue O, Adebusoye SO, Betiku AO, and Oluwole AO

Table 1: Demographic distribution of Respondents

\begin{tabular}{|c|c|}
\hline Characteristics & Frequency (Percent) \\
\hline Age (years) & \\
\hline $21-30$ & $25(16.3 \%)$ \\
\hline $31-40$ & $70(45.4 \%)$ \\
\hline $41-50$ & $46(29.8 \%)$ \\
\hline $51-60$ & $9(5.9 \%)$ \\
\hline $61-70$ & $4(2.6 \%)$ \\
\hline Sex & \\
\hline Male & $84(54.5 \%)$ \\
\hline Females & $70(45.5 \%)$ \\
\hline Marital Status & \\
\hline Married & $129(83.8 \%)$ \\
\hline Single & $23(14.9 \%)$ \\
\hline Widowed & $2(1.3 \%)$ \\
\hline Religion & \\
\hline Christianity & $134(87.0 \%)$ \\
\hline Islam & $20(13.0 \%)$ \\
\hline Professional Status & \\
\hline Medical doctor & $78(50.6 \%)$ \\
\hline Nurse & $51(33.1 \%)$ \\
\hline Others & $25(16.3 \%)$ \\
\hline Duration of professional practice (years) & \\
\hline$\leq 5$ & $16(10.4 \%)$ \\
\hline $6-10$ & $43(27.9 \%)$ \\
\hline $11-15$ & $30(19.4 \%)$ \\
\hline $16-20$ & $41(26.6 \%)$ \\
\hline$>20$ & $24(15.6 \%)$ \\
\hline Access to medical health insurance coverage & \\
\hline Yes & $30(19.5 \%)$ \\
\hline no & $124(80.5 \%)$ \\
\hline
\end{tabular}

Table 2: Response on Visual Health attitudes

\begin{tabular}{|c|c|}
\hline Response & Frequency (Percent) \\
Yes & $131(85.1 \%)$ \\
No & $23(14.9 \%)$ \\
History of previous Eye examination & $63(40.9 \%)$ \\
No & $87(56.5 \%)$ \\
Not sure & $4(2.6 \%)$ \\
\hline History of dilated ophthalmoscopy & $4(2.6 \%)$ \\
< 3 months & $9(5.8 \%)$ \\
3-6 months & $29(18.8 \%)$ \\
$>$ 6months & $112(72.7 \%)$ \\
\hline Frequency of Eye clinic Visits & $117(76.0 \%)$ \\
\hline Awareness of common eye conditions & $116(75.3 \%)$ \\
Cataract & $129(84.0 \%)$ \\
Glaucoma & $114(74.0 \%)$ \\
Refractive errors & $110(71.0 \%)$ \\
Diabetic eye disease & \\
Retinal disease &
\end{tabular}


Attitude and Perception of Healthcare Professionals in Ogun State Towards Their Visual Health

\begin{tabular}{|c|c|}
\hline Affectation by any of the common eye conditions & \\
Cataract & \\
Glaucoma & $3(1.9 \%)$ \\
Refractive errors & $8(5.8 \%)$ \\
Diabetic eye disease & $54(35.1 \%)$ \\
Retinal disease & $1(0.6 \%)$ \\
& $2(1.3 \%)$ \\
\hline Family history of Glaucoma & \\
Yes & $30(19.5 \% 0$ \\
No & $116(75.3 \%)$ \\
Not sure & $8(5.2 \%)$ \\
\hline
\end{tabular}

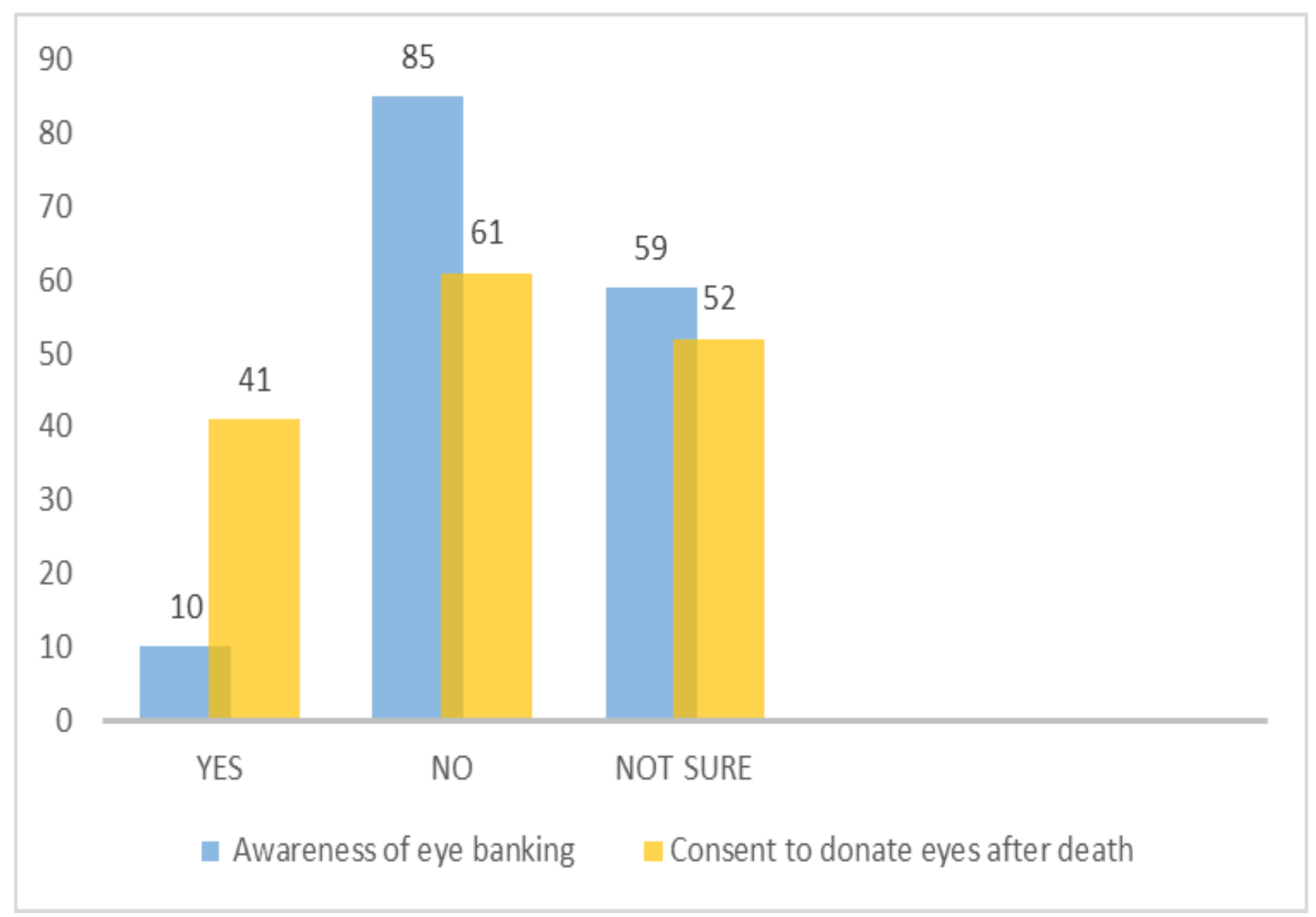

Figure I: Bar chart of responses to awareness and consent to eye banking 


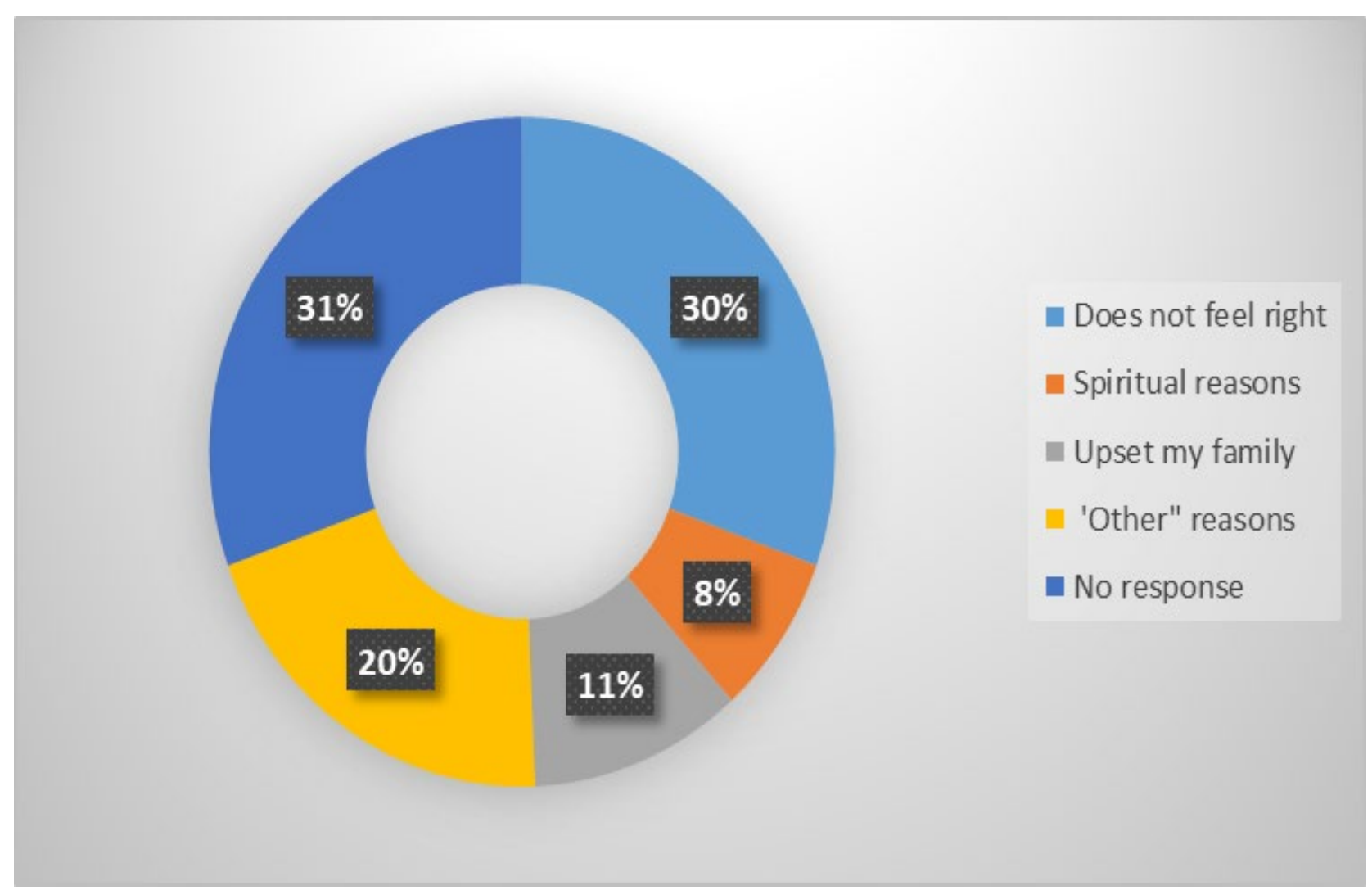

Figure II: Chart of reasons for non-consent for eye donation after death

\section{DISCUSSION}

There was a poor response rate from other HCP who were not doctors or nurses, thus they were analyzed as 'others' and accounted for $16.3 \%$ of the respondents.

There was a good male to female distribution amongst the participants and the age distribution showed that most of the participants were between 31-50 years of age.

Practically all participants felt their general health rated between good to excellent as expected of health professional 5 but when it came to their visual health only $41 \%$ had ever had a dilated ophthalmoscopy despite the fact that $85 \%$ had visited an eye clinic before for varied complains. This could imply that about $59 \%$ of the HCP had never had a comprehensive eye examination carried out or seen an Ophthalmologist.

The lack of health insurance coverage as found amongst $80.5 \%$ of the respondent could be a major barrier to accessing eye care as documented by Garfield et al8. They found that uninsured patients were more likely to skip preventive health checks like mammograms, pap smears, cholesterol and blood sugar test etc and also that $20 \%$ of these uninsured patients also skipped recommended hospital treatments as compared to only $3 \%$ of their insured patients8. This also supports our finding where $40 \%$ of the insured HCP had regular eye checks of at least 6 months as compared to $24.2 \%$ of those not insured.

Provision of health insurance coverage especially for the low-income HCP is of outermost importance in ensuring routine health checks are carried out as at when due.

One hundred and twelve $(72.7 \%)$ respondents said they rarely went for eye checkups even though the general recommendation is to have routine checks every 2 yrs especially for those with a family history of Glaucoma or those over the age of 40 years so as to prevent avoidable blindness1. This is further corroborated by the significant association of the presence of eye conditions among those aged 40 yrs and above in this study.

It was surprising to find out that about $30 \%$ of the HCP had never heard of common eye conditions like Cataract, Glaucoma, Diabetic eye disease, and Retinal diseases. A lack of awareness of these potentially blinding eye diseases has also been reported as another major barrier to accessing preventive or comprehensive eye care in Nigeria9.

Refractive errors were the commonest cause of eye disease amongst the respondents as also documented globally2. The prevalence of Cataract (1.9\%) and Glaucoma (5.8\%) was low amongst these respondents, this may be because $91.4 \%$ were 50 years and below and these conditions are more prevalent after 50 yrs 2 . 
With regards to Eye banking, only $6.5 \%$ were sure Nigeria had an Eye bank and only $41 \%$ of the respondents said they would be willing to donate their eyes after death for Vision restoration (Fig I). This unwillingness to give consent for donation is responsible for the global shortage of cornea graft tissue, where only one is available for 70 needed corneas10. There is thus a need for more advocacy in Nigeria via various educational media to change the mindset of Africans towards tissue donation. This is very important because even most (69\%) Ophthalmologist in a Nigerian survey declined to give consent for cornea donation due to traditional beliefs, social implications etc4.

Doctors were shown to be most willing to donate amongst the respondents as seen in Mexico11 and also in Ethiopia, where adults with lower educational levels were less willing to give consent for cornea donation12.

Christians were found to be more willing to donate their eyes than Muslims in this study, as also documented in the global survey to review 283530 donated eyes where consent was given mainly by Christians, followed by Muslims and then Buddhist12.

\section{CONCLUSION}

There was a poor attitude to assessing visual health care and a low awareness of Eye banking and its importance among the HCP. Though the doctors were more willing to give consent for eye donation, there is a strategic need to reinforce positive visual health and post mortem eye donation amongst all HCP, so they can influence their patients more positively.

Recommendations: Positive visual health attitude should be promoted during the training programs of HCP. There is also an urgent need for sensitization of HCP on the importance of voluntary post mortem eye donation.

Limitation: The poor response of the other HCP to this survey may have been due to lack of internet to access the online survey.

\section{SOURCES OF FUNDING}

This research received no specific grant from any funding agency in the public, commercial, or not-for-profit sectors.

\section{CONFLICT OF INTEREST}

The author have declared that no competing interests exist.

\section{ACKNOWLEDGMENT}

None.

\section{REFERENCES}

[1] Universal Eye Health: A https://www.who.int/blindness/AP2014_19_English.pdf?ua=. Accessed 15/06/2020.

[2] Blindness and vision impairment. www.who.int/news-com/fact-sheets/details/blindness-andvisual.impairment. Accessed 16/06/2020.

[3] Bourn RRA, Flaxman SR, Braithwaite T, Cicinelli MU, Das A, Jonas JB et al. Magnitude, temporal trends and projections of the global prevalence of blindness and distance and near visual impairment: A systematic review and meta -analysis. Lancet Glob Health 2017;5 (9): 888-97.

[4] Joseph M, Erameh W, Afehide OE, Edema OT. Knowledge and attitude of Nigerian Ophthalmologist towards cornea donation and cornea graft. Journal of medicare and biomedical research 2007;6 (1): 26-34.

[5] Wiskar K. Physicians health: A review of lifestyle behaviors and preventive health care among physicians. BCMJ 2012; 54 (8): 419-423.

[6] Helfand BK,Mukamal KJ. Health care and lifestyle practices of Health Care Workers: Do Health care workers practice what they preach?. JAMA Intern Med 2013; 173 (3): 242-244. 
[7] Scott AW, Brussler NM, Ffolkes S, Wittenborn JS, Jorkasky J. Public attitudes about eye and vision health. JAMA Ophthalmol 2016. Doi.10.1001/jamaophthalmol.2016.2627.

[8] Garfield R, Orgera K, Damico A. The uninsured and the Affordable Care Act: A primer key facts about Health Insurance and the uninsured amidst changes to the affordable care act 2019. www.kff.org/reportsection/the-uninsured. (Accessed 21/07/2020).

[9] Okoye RS, Bell L, Papadolous I. Barriers to accessing good eye care services in Nigeria: A focus on Anambra State. JNOA 2018; 20 (1): 30-37.

[10] Gain P, Jullenne R, He Z, Aldossary M, Acquart S, Cognasse F, Thuret G. Global survey of corneal transplantation and eye banking. JAMA Ophthalmol 2016; 134 (2): 167-173.

[11] Mercado-Martinez FJ, Padilla-Altamira C, Diaz-Medina B, Sanchez-Pimienta C. Veiws of health care personnels on organ donation and transplantation: A literature review. Texto context-Enferm 2015; 24(2): 574-583.

[12] Hussen MS, Belete GT. Knowledge and attitude towards eye donation among adults in Northwest Ethiopia: A community based cross sectional study. Middle East Afr J Ophthalmol 2018;25: 126-130. 